Espacio y Desarrollo No 27, 2015, pp. 57-78 (ISSN 1016-9148)

http://dx.doi.org/10.18800/espacioydesarrollo.201501.003

\title{
LOS NO LUGARES Y EL MUNDO DE LAS AGUAS: APROXIMACIÓN AL TERRITORIO ANCESTRAL DE UNA COMUNIDAD INDÍGENA AMAZÓNICA
}

\author{
Ronald Fernando Quintana Arias* \\ Universidad Distrital Francisco José de Caldas, Bogotá - Colombia \\ ron902102004@gmail.com
}

\section{RESUMEN}

Se realizó una caracterización ancestral del territorio de la comunidad indígena de Macedonia (Amazonas colombiano ubicada a $57 \mathrm{~km}$ de Leticia río arriba) a partir del análisis de mapas culturales obtenidos de una metodología etnográfica sustentada en cartografía social y un análisis a través de procesos intersubjetivos de consensualización.

Como resultado, se obtuvieron mapas georreferenciados que generan un «no lugar» fuera de su campo habitual (espacio urbano), al integrarse este al "macroespacio chamanístico", el cual genera la esencia del sentido primordial de la comunidad, lo que a su vez sirve para generar una revalorización cultural local que fomenta procesos de «glocalización» en el marco de la "globalización».

Palabras clave: Amazonas, cartografía social, etnografía, mapas.

Non-places and the world of waters: Approaching to the ancestral territory of an Amazonian indigenous community

\section{Abstract}

Characterization of an ancestral territory of the indigenous community of Macedonia was performed (Colombian Amazon located $57 \mathrm{~km}$ upstream from Leticia); through the cultural maps analysis obtained of ethnographic methodology based on social mapping and one analysis through intersubjective processes of consensualización.

As a result, georeferenced maps that generate a «no place» outside their usual field (urban area) were obtained, to integrate a "macro-space shamanic» which creates the essence of primordial sense of community, which in turn serves to create a local cultural appreciation that promotes processes of "globalization» in the context of "globalization».

Key words: Amazon, Social Cartography, Ethnography, Maps.

B.Sc, Magíster en Desarrollo Sustentable y Gestión Ambiental. 


\section{LOS «NO LUGARES» Y EL MACROESPACIO CHAMANÍSTICO}

El buscar una aproximación al territorio ancestral de una comunidad indígena amazónica, lleva a revaluar el concepto de un no lugar, como aquel espacios que solo permiten «ser» cuando se aporta la identidad (Auge, 1992), por ende la descripción del mundo en términos abstractos sirve para formar un lazo afectivo entre el lugar (Tuan, 2007) y la gente — «actor geográfico»— (Caneto, 2000); en donde la percepción del territorio (contacto directo con el espacio) junto a su cognición (espacios en donde el «actor geográfico» nunca ha estado presente) aportan elementos simbólicos ${ }^{1}$ que van a incidir en la concepción y valoración del espacio.

De esta forma, se ha generado una revaluación de las nociones mecanicistas de la idea del espacio bajo las nociones físicas (grande, alto, ancho, largo, pequeño), al relativismo de las dimensiones dependiendo del punto de vista del observador (Fals Borda, 2000). Esto capacita al ser humano para moverse tanto en el tiempo como en el espacio, al facilitar el entendimiento del mundo, describiendo el aquí y el ahora, situando un «todo» en el mismo, a través de los mapas (Rae, 1999), lo que se puede evidenciar en los mitos y su importancia en el orden del mundo y el cuidado del medio ambiente.

De acuerdo a la cosmovisión de las «etnias de río» (la fuente hídrica mayor depende de la etnia), este se originó por el árbol mítico que en su caída le dio forma a la gran cuenca y a los mundos (tierra, cielo, agua); caracterizando, en este caso a la Amazonia como un lugar grande y diverso en aspectos tales como: natural, geológico, climatológico, flora, fauna, agua, y también en lo que se refiere a las sociedades y culturas que la ocupan. "La asignación de un territorio a cada grupo nace de la necesidad cultural de definir entidades discontinuas que permita un ordenamiento que evite el caos [...] que sirva para vivir bien» (Van der Hammen, 1991, p. 131); por lo que la asignación, como las pautas de organización y reconocimiento de los territorios tribales se relaciona con sitios predeterminados del paisaje: «el lugar de nacimiento mítico».

En este orden de ideas los habitantes del espacio estudiado territorializan su cuerpo y le incorporan a partir de sus rituales, poderes de esencias (dueños) como parte integral del «ser» (mundo), convirtiendo el espacio geográfico en el que nació el grupo, no solo en la fuente de la identidad étnica, sino en la base del «macroespacio chamanístico». A partir de esto las asociaciones territoriales generan redes entre malocas ${ }^{2}$ (Reichel, 1987) y túneles entre territorios y otros mundos que solo conocen y tienen acceso los chamanes. Van der Hammen (1991) reportó la existencia de túneles subterráneos que le fueron relatados por «Chapune«, y le atribuyó a estos el desplazamiento de peces

\footnotetext{
Escobar, M. (1992), Los lugares, los grupos y la diversidad social, citado en Alvarado Quetgles et al. (1999).

2 «Casa ancestral utilizada por los indígenas del Amazonas en donde su asignación mítica y diferencias en formas por los grupos étnicos se debe a su "propia brujería" (Van der Hammen, 1991, p. 138), debido a esto se puede considerar la unidad básica de ocupación del territorio» (Quintana, 2011, p. 106).
} 
del río Caquetá a los lagos medios de Mirití, lo que puso en evidencia la existencia del «territorio chamanístico» que se puede entender a través de la maloca.

En este sentido, estudios recientes han demostrado la existencia de grandes acuíferos naturales en la Amazonía con un volumen calculado de 160 billones de metros cúbicos que representa el 80\% del total de agua de la Amazonía (Amazônia tem, 2014). Por ende el reconocer a su entorno llevo a los indígenas a representar en la maloca al universo en un sistema concreto, haciéndolo accesible y posibilitando acciones sobre él.

La ubicación de cada poblado humano se relaciona con los mitos de origen afianzando las asociaciones territoriales como un «orden del mundo» dado por las serpiente ancestral (Diïjoma, Yakuruna, Añiraima), lo que a su vez establece modelos de relaciones sociales y manejo espacial para cada etnia, posicionándola como la fuente del manejo del territorio, en cuyas relaciones confluye la esencia del «sentido primordial» (territorio-hogar). Esto convierte al territorio en cuerpo, historia (mítica, ritual y humana), memoria (moral y política), fuente (poder, defensa, identidad, cohesión étnica) y vida (Quintana, 2013).

Para empezar, se debe tener en cuenta que la Amazonía ha estado ocupada por grupos humanos desde aproximadamente 10000 años (Hooghiemstra \& Van der Hammen, 1998), por lo que se establecieron relaciones con el entorno "naturaleza», que por el contacto europeo fueron diezmadas y desplazadas por la mentalidad extractivista. De esta manera, la Amazonía como «despensa» se incorporó en la globalización, y por ende en disputas territoriales de países para los cuales ha sido una frontera remota.

En consecuencia, el legado europeo dejó una visión de territorio desde el «pensamiento científico", un espacio geográfico cartografiable y delimitado, que define la soberanía de un poder político, encargado de administrar, controlar y defender los recursos (territorio-capital) y los grupos humanos que allí se encuentran, un territorio que existe independientemente de los humanos aunque estos le den sentido (Quintana, 2013).

A partir de las características mencionadas anteriormente, el entrecruzamiento entre indígenas, europeos y africanos generó una complejidad cultural, social y política; y formó una población rural amazónica, que vive de la selva y de las aguas, una «sociedad bosquesina» de raigambre indígena, mestiza, pluriactiva, igualitaria, anárquica, festiva y multilingüe (Gasché \& Echeverri, 2003), que por la interacción con el mercado y las ciudades obtuvo acceso a la educación y a los servicios públicos estatales. Debido a esto, la mentalidad "extractivista» de herencia europea, tomó un giro multicultural y ambientalista, y se fomentó la formulación de políticas de protección y conservación cultural y natural (Echeverri \& Pérez Niño, 2011), «que en el caso de Colombia se refleja en la institución de resguardos indígenas en la década de los 80 y la Constitución política de 1991»(Quintana, 2013, p. 99).

[...] la presencia del Estado ha generado una homogenización de las diferencias (lógicas territoriales) camufladas en una política de «unidad nacional», cuyo fortalecimiento de las especificidades étnicas y culturales no tiene en cuenta que el hecho de que las etnias 
compartan un «macroespacio chamanístico» implica un «orden del mundo», en donde el manejo del espacio territorial, es un «legado supra étnico de cuidado en conjunto de este gran ser (Planeta Tierra) (Quintana, 2013, p. 100).

Las diferencias de concepciones de mundo entre las lógicas territoriales indígenas y occidentales, han llevado a reconocer de diferente forma la problemática de la protección y conservación cultural y natural por parte de estos dos actores. Como respuesta a lo anterior se genera la ley 388 de 1997 y la ley 1454 de 2011, pero al ser leyes que tratan de integrar una lógica indígena ${ }^{3}$ y una lógica occidental ${ }^{4}$ en un territorio caracterizado por el conflicto armado (cultivos ilícitos) y políticas de explotación por parte del gobierno (cultivos agroindustriales, hidrocarburos, minerales y represas hidroeléctricas) (Quintana, 2013), surge la necesidad de establecer mesas de negociación bajo una metodología participativa en la búsqueda de estrategias para dar solución a las problemáticas.

\section{DiNÁMICAS históricas DEL MUNDO DE LAS AGUAS}

La búsqueda de evidencias que dan cuenta de la similitud entre el arte rupestre y el mito (Lévi-Strauss, 1971), han ayudado al planteamiento y reconsideración de hipótesis que aportan al establecimiento de secuencias culturales, indispensables para la comprensión de la historia; lo que hace que este tipo de descubrimientos vayan más allá de lo estético, pues enmarca la relación entre la naturaleza y el ser humano como una parte fundamental de la historia cultural (Urbina, 2010).

Asimismo, estas características ponen en evidencia una temporalidad histórica que da cuenta de desarrollos autóctonos, que propician la reevaluación de la "necesidad» de recurrir a la traslocalización disfrazada en préstamos culturales, que hacen ver al indígena dependiente e incapaz. Esta característica ha cubierto el genocidio cultural más largo de la historia ya que no solo se limitó a la extracción del «oro verde» de sus territorios (Quintana, 2009), sino que trajo consigo el desprecio por el mayor de sus tesoros: «el espíritu indígena» y convirtió el arte (oral, artesanías, petroglifos, música y pinturas) en las armas que perduraron más allá del silencio: en una «sombra invisible» (Quintana, 2011).

De esta manera, la relación entre la serpiente y el ser humano ha sido una característica común de diversas etnias de la Amazonía; el mitema que convoca la unidad de estas a través de la idea mítica de un origen común (Diïjoma, Yakuruna, Añiraima),

\footnotetext{
Privilegia un centro vital sobre el límite, «condensa» el tiempo, tiene una visión de «territorio-hogar» (espacio humanizado), opone gente humana y no humana (Quintana, 2013).

4 Privilegia el límite para demarcar su ámbito, con una visión lineal del tiempo, visión de «territoriocapital» que opone lo natural a lo cultural (Quintana, 2013).
} 
enmascarando en esta relación la esencia del sentido primordial de la humanidad y la fuerza demiúrgica que asignó un lugar no solo en un espacio geográfico sino en «el concierto universal» (Quintana, 2013).

El mito caracteriza el espacio, condicionando el primer contacto con la naturaleza (Quintana, 2009), forma parte de la estructura social ya que genera los canales de comunicación no solo con los abuelos, con las plantas y animales sagrados «los dueños», sino con el pasado, presente y futuro. Por consiguiente, el manejo del mundo implica relaciones con los seres de este mundo y los del mundo espiritual (Van der Hammen, 1991), lo que a su vez enriquece y caracteriza la visión de medio ambiente que se tiene dentro y fuera de la comunidad.

Debido a la expansión europea y africana en el espacio geohistórico americano, se generaron unas historias resultados de las ideas, sentimientos, creencias, opiniones y actitudes del encuentro de los tres mundos, y forjaron una mentalidad colectiva reflejo de la nueva sociedad donde se desenvolvían (Magasich \& De Beer, 2001).

La mezcla de ideales caballerescos, religiosos y mercantilistas españoles así como la asimilación de sistemas productivos indígenas por parte de los invasores (europeos y africanos), generaron diferentes «neo-etnias» (Mosonyi, 1982) caracterizadas por la relación que entre ellos se establecía. Lo que les dio a los indígenas un rol unificador que ocasionó la «indianización» del español y el africano, como parte de un sistema de respuesta para la subsistencia por la inserción forzosa en sociedades previamente organizadas (Acosta Saignes, 1961).

A partir de lo anterior, los antecedentes étnicos indígenas cobran importancia en la conquista debido a la diversidad de etnias aborígenes sometidas a los procesos de trasfiguración cultural, variabilidad del modo de producción-subsistencia y diversidad de ecosistemas; lo que sumado a los procesos irregulares de conquista en cuanto a la épocas y modelos de penetración junto al mestizaje dieron lugar al «mito del nuevo mundo" y la dinámica interétnica se convirtió en una fuerza interfecundante y complementaria, en oposición a la dinámica interclasista que deviene en conflictividad y genocidio (Mosonyi, 1982).

Los ideales caballerescos, las creencias y ritos característicos de la Edad Media se mezclaron con aspiraciones aristocráticas, ideales mercantilistas e imágenes de un mundo lleno de nuevas cosmovisiones; convirtiendo a las ciudades pérdidas, los tesoros y los mundos indígenas, en las fuerzas míticas e impulsadoras de la conquista. En este orden de ideas, lo viejo y lo nuevo se entrelazaron reproduciendo sus esencialidades; en donde la mitología indígena enriqueció la española al fijar actitudes y decisiones de los dirigentes que rigieron los cambios y metas de la sociedad (Gandia, 1929; Galán-Zapata, 1963; Metraux, 1973; Vigneras, 1976; Ocampo, 1988), lo que estimuló la colonización de nuevos territorios y dio origen a una "aculturización antagonista" por las dinámicas transculturales (Devereux, 1975). 
Esta hibridación cultural generó que los europeos proyectaran sus tesoros en el «nuevo mundo». Es así que los mitos de El Dorado, Metha, Xeira, Árbol de la vida (Wochine en el Amazonas), Mundo de las aguas (Yakuruna); crearon el estímulo que propició la conquista, quienes a pesar de no poder explicar el mito indígena desde las ideas y tradiciones mitológicas europeas, si proyectaron la realidad de los recursos naturales, la belleza de los paisajes y escasamente la profundidad de las tradiciones indígenas (Quintana, 2014).

\section{RELACIONES ECOLÓGICAS INDÍGENAS}

La explicación de la razón del control del mundo se encuentra en los mitos de las etnias, y es la maloca el espacio en donde ese «no lugar» marcó la percepción del «mundo chamánico» y las redes de pensamiento que generaron un modo de vida que propendió por el cuidado del medio ambiente convirtiendo la relación entre salud-naturalezacultura completa e indisoluble (Quintana, 2013).

En este sentido, los indígenas propendían por el cuidado del medio ambiente con una visión de sustenibilidad, lo que se ratifica en algunos estudios que indican que para etnias como los kasajos y mohawks la toma de una decisión de importancia, debía contemplar la invocación de siete generaciones de antepasados para discutir el efecto de dicha decisión sobre las siete próximas generaciones (Olivella, 2008), lo que demuestra un movimiento cíclico entre la cultura y la naturaleza, a través de una relación de tiempo indígena bidireccional en donde el futuro puede esta atrás y el pasado adelante (Gavilán-Pinto, 2012).

Esta relación chamánica integró para los indígenas el mundo de lo natural y sobrenatural en un concepto de sustentabilidad que fue alimentada por la relación hombrenaturaleza dada por el primer contacto que se establece con ella, lo que condiciona las acciones sobre esta (Quintana, 2009). En este sentido, las diferentes «visiones de naturaleza» por parte del indígena, se han debido a cambios históricamente introducidos desde mucho antes del «descubrimiento» (encubrimiento) de América; por lo que si «la naturaleza pertenece al ámbito de la cultura, se deben tener en cuenta los patrones culturales para entender las acciones sobre ella» (Van der Hammen, 1992, p. 3, )

Estos cambios culturales históricos antes del «descubrimiento» de América determinaron una relación entre los pueblos y su entorno por medio de una historia ambiental así como una social de las semillas (Quintana, 2009), lo que facilitó en la región donde se ubican estos pueblos un arreglo espacial óptimo que maximizó la integridad ecológica a través de un buen uso de la tierra (Forman, 1995).

Es de destacar que después de más de 500 años de un coloniaje (refundación de ciudades constituidas) (Blanco, 2001), un neocoloniaje (imaginarios míticos con ideales caballerescos acompañado de misiones católicas y/o protestantes) (Hemming, 1984) y una república que fue más cruel que la misma colonia (al permitir las matanzas de la casa 
arara, las caucherías, el narcotráfico y un conflicto armado que no solo afectó a las comunidades indígenas sino las afrodescendientes); fue solo hasta 1991 que una constitución en Colombia le da un reconocimiento real a los pueblos indígenas; por lo que es ilógico pensar que la solución a la problemática de las relaciones ecológicas de los indígenas con su entorno está pronto a resolverse, y más aún si se tiene en cuenta que muchas leyes que propenden por la perpetuidad cultural tienen otra ley que va en contra, argumentada en políticas extractivistas y de control y manejo de los recursos (Quintana, 2013).

Esto ha llevado a que en el trabajo realizado en la comunidad muchas de las personas mestizas, afrodescendientes e indígenas no nieguen su herencia indígena o africana pero la subestimen, haciendo sobresalir el «blanqueamiento» que el mestizaje ha llevado a la comunidad, por lo que se considera que el ser indígena es una transición que llevará a que los nińos en el futuro sean iguales a los occidentales, y a su vez ha condicionado una visión de desarrollo que no se diferencia al crecimiento económico.

Este intento de equiparar la igualdad (bienestar merecido) con la diferencia (diversidad) (Mosonyi, 2006), es alimentada por el hecho de no sentirse satisfechos en sus aspiraciones y un encuentro religioso que contempla como incompatible lo pluricultural $\mathrm{y}$ ve las distintas espiritualidades como no convergentes hacia valores interculturales.

Por otro lado, si se viera la convergencia de los valores interculturales no se fomentaría una exclusión desde el pluralismo camuflada en la tolerancia; lo que no significaría un nuevo "mestizaje» que trate de sacar lo mejor de cada cultura, sino el reconocimiento de las diferencias que llevan a un respeto que enriquece a los actores involucrados, permitiéndoles ser uno dentro de lo múltiple.

En este sentido, partir del hecho de que «no se puede entender al hombre solo con la razón» (Jung, p. 21, 1921) podría generar soluciones para la adaptación de la sociedad humana occidental a los procesos que existen en la naturaleza (Nielsen $\&$ Jorgensen, 1996). Pero solo será en la integración de los territorios (indígena-occidental) en la que la ecoeficiencia, la biomímesis (Riechmann, 2009) y la articulación de lo económicosocial-natural, que se llegarán a generar propuestas sostenibles fuera del marco de contextos insostenibles; una sustentabilidad «real» a escala planetaria.

\section{Metodología}

El presente trabajo tuvo un enfoque de estudio de caso con una sola unidad de observación (comunidad indígena de Macedonia, ubicada en el trapecio amazónico colombiano), el tipo de investigación fue etnográfica con base en la investigación-acción-participación (IAP). En este sentido, se parte de los postulados de Orlando Fals Borda acerca de la IAP al cambiar la visión de sujeto-objeto provocando una reacción reflexiva en la comunidad (Rahman \& Fals Borda, 1991), teniendo herramientas de tipo etnográfico (consultas a manera de entrevistas y cartografía social) para la obtención de información. 
A su vez la participación no buscó una asimilación acrítica de un marco global de partida con el que se propone un compromiso, sino una recapitulación sobre el conjunto de procesos que condicionan la vida social de la comunidad de Macedonia, con el objeto de generar una eventual modificación de la misma.

La organización del análisis convierte a la IAP en una pedagogía constructiva (Merino \& Raya, 1993), donde el conocimiento es un proceso que genera una «maduración colectiva» (De Miguel 1993), al posibilitar un vínculo entre los actores sociales y el investigador, generando tejidos que permiten un diálogo de saberes (Fals Borda, 1992).

La investigación etnográfica tuvo un enfoque denominado por Arocha (1991) como "procesos intersubjetivos de consensualización", el cual al establecer relaciones trasversales a través de la confrontación entre lo que se hace, el beneficio que tiene hacerlo y la importancia en la función que desempeña, lleva a una conciliación entre los enfoques etnográficos némicos (desde adentro o subjetiva) y néticos (desde afuera u objetiva). Lo anterior permitió conocer a través de herramientas etnográficas como la consulta a manera de entrevista y la cartografía social, los vínculos, redes y conocimiento que poseen los indígenas de Macedonia sobre el territorio y su sociedad.

Teniendo como referente los mapas desarrollados en la comunidad a partir de la cartografía social, se obtuvieron 685 puntos georreferenciados en terreno de 3410 hectáreas con el GPS (Garmin 62sc con precisión submétrica) que se verificaron con imágenes de satélite obtenidas de Google Earth. De esta manera se elaboraron unos mapas con el sistema de coordenadas MAGNA SIRGAS, coordenadas elipsoidales WGS 84 con coordenadas planas Gauss-Krüger, los planos cartográficos fueron digitalizados en polígonos cerrados en ArcGIS.

Cabe resaltar que todo el trabajo y las consultas a manera de entrevistas realizadas en la comunidad (septiembre y octubre de 2013) fueron autorizadas para su publicación por el cabildo indígena, quien dio el aval para la realización del trabajo y subvencionó una parte del proyecto en campo, el cual fue financiado casi en su totalidad por el Centro de Investigaciones y Desarrollo Científico de la Universidad Distrital Francisco José de Caldas (CIDC).

\section{Resultados}

Los mapas culturales fueron el resultado de la contratación de mapas obtenidos de fuentes como Google Earth, Instituto Geográfico Agustín Codazzi, Instituto Colombiano para la Reforma Agraria (Incora) y Parques Nacionales Naturales de Colombia, junto al mapa obtenido de los talleres de cartografía social (Figura 1) realizados y socializados en la comunidad por líderes indígenas (Figuras 2-5). 
Lo anterior generó una aproximación real al territorio de la comunidad que trasciende de un lugar cartografiable, medible y lineal a un «no lugar» generador del universo indígena en el que se basa todo el conocimiento tradicional, el desdoblamiento del tiempo y el macroespacio chamanístico (Quintana, 2013). Por ende, se habla de lugares sagrados donde se originan un ciclo imperceptible de energía, propia, diversa, femenina, que orienta al cuerpo indígena aún en construcción a diferencia de su alma, a un camino familiar que conduce a la unidad, "un kü ru Na»"5 a través de un inconsciente colectivo.

\section{Elaboración y socialización de los mapas en la comunidad}

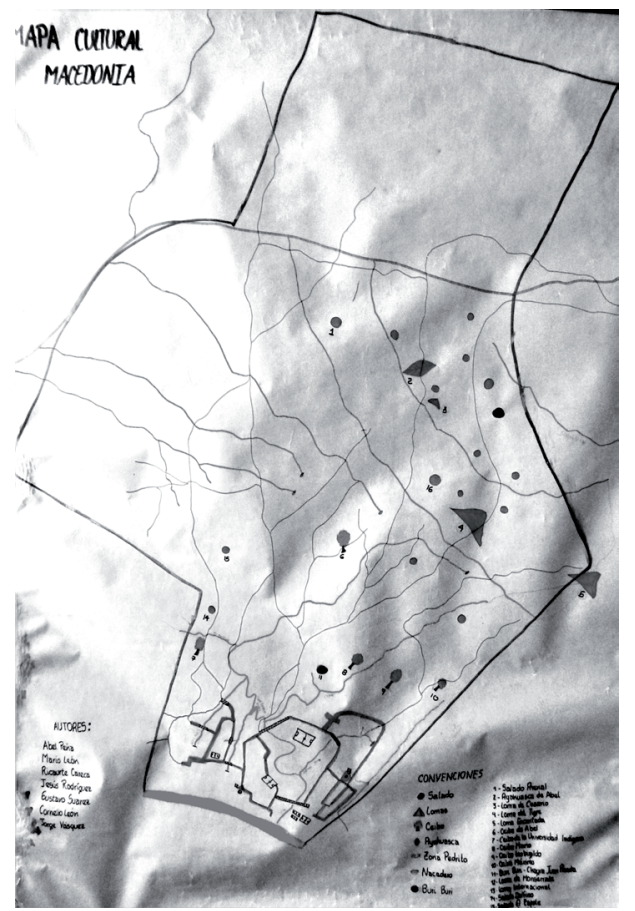

Figura 1. Mapa cultural de Macedonia. Foto: Ronald Quintana, 2013.

5 Esencia de lo masculino y femenino. 


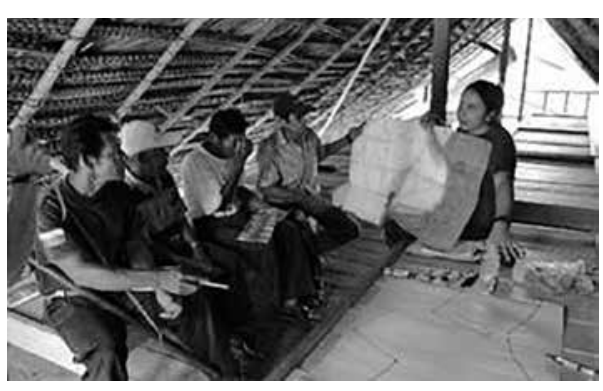

Figura 2. Socialización de los objetivos. Foto: Ronald Quintana, 2013.

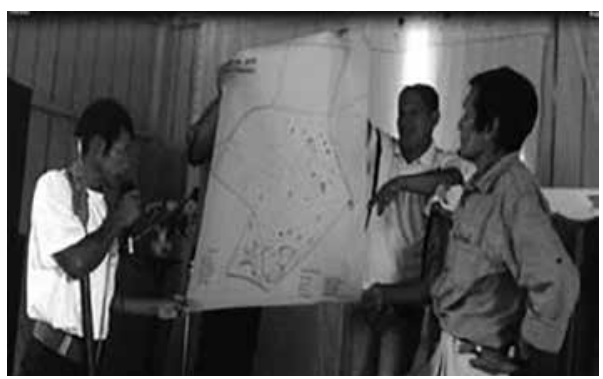

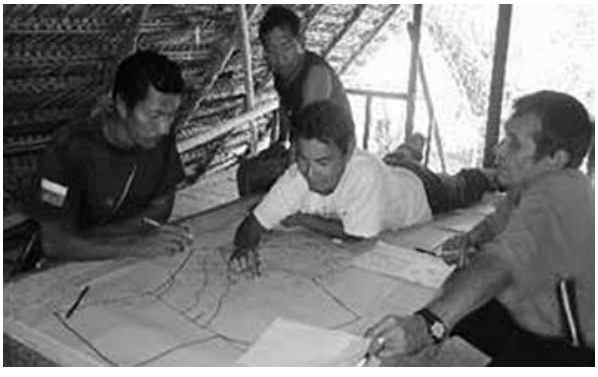

Figura 3. Realización de los mapas. Foto: Ronald Quintana, 2013.

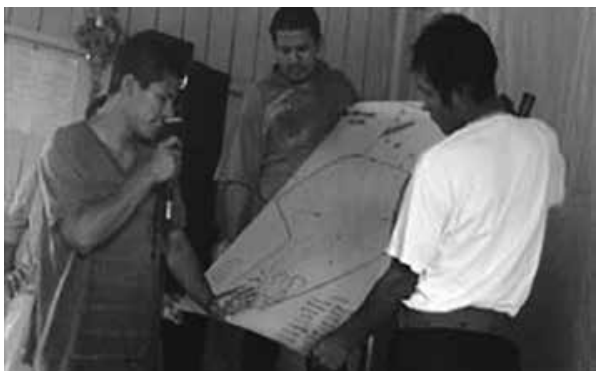

Figuras 4 y 5. Socialización de los mapas ante toda la comunidad. Foto: Ronald Quintana, 2013.

Por otro lado, vivir contradicciones como resultado de la herencia de historias de violencia (capos de la mafia), guerras (conflicto armado Perú-Colombia), religión (propia e impuesta) y política ha reconfigurado el equilibrio y la expresión de vida de la naturaleza, cuya relación ancestral le dio a los indígenas la enseña que tener la posibilidad de hacer algo no significa que se deba hacer.

En el mapa cultural general (Figura 13) se identifican los lugares que los moradores de Macedonia consideran sagrados. De esta manera, se destaca la loma Encantada, la loma del Tigre y la loma de Cesario. Es de resaltar que las lomas identificadas se caracterizan por ser lugares sagrados por diferentes características; la loma de Cesario se asocia con la presencia de varios animales debido a que esta se encuentra cerca de un salado (lugar donde se reúnen varias especies de animales). La loma del Tigre es reconocida como un lugar donde los antiguos moradores avistaban tigres, se dice que en esta siempre había un tigre que arañaba un árbol, y finalmente la loma Encantada la cual se dice es un camino al mundo subterráneo (Figuras 6-8). 


\section{LOMA EnCANTAda}

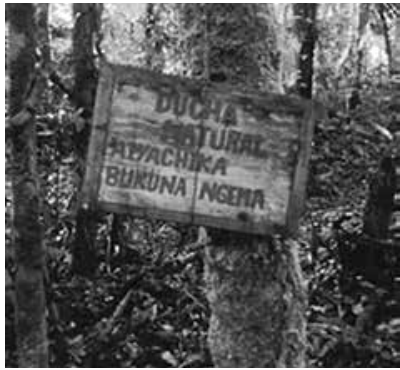

Figura 6. Ducha natural. Foto: Ronald Quintana, 2013.

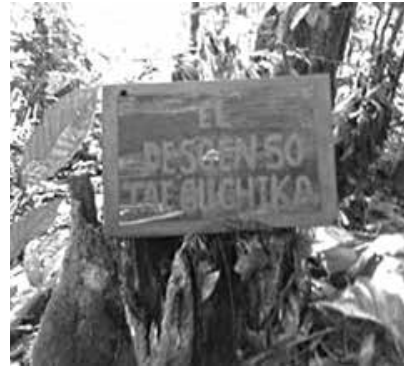

Figura 7. Final del camino. Foto: Ronald Quintana, 2013.

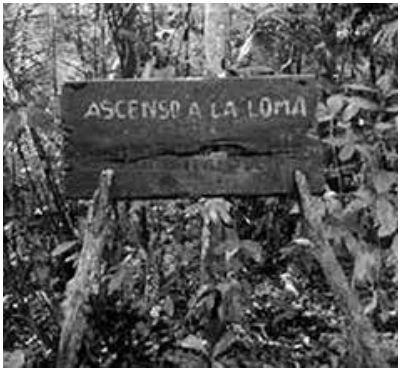

Figura 8. Inicio del camino. Foto: Ronald Quintana, 2013.

$\mathrm{Al}$ respecto de la loma Encantada se obtuvieron los siguientes relatos de abuelos de la comunidad:

«[...] antiguamente los primeros ancestros que vivían por aquí, entonces ellos decían que llegaban los tigres aquí en esta loma, aquí vivían, este es un lugar como sagrado Loma del tigre. Entonces pues tenemos también donde el tigre descansa y come la presa hay un palo allá en la bajadita, ahí. Antiguamente [...] había un camino que pasa bien por ahí al borde de la lomita, pues ello cuando venían [...] miraban al tigre descansando, comiendo la presa [...] por eso ellos le llamaban loma del tigre [...] abajo no se sabe si hay personas encantadas $[\ldots]{ }^{6}$.

El relato anterior establece la importancia cultural de un lugar de potencial turístico de la comunidad como lo es la loma del Tigre, actualmente es un lugar de actividad turística y representa un ingreso para todos aquellos que brindan este servicio en la comunidad.

«[...] antiguamente había una puerta acá en esta loma encantada, como una puerta de una iglesia ancho que lo lleva a uno allá adentro, es oscuro pero allá había un mansito que se llamaba Gabriel, Gabriel Tangarife el entro como tres veces allá y traía chicha de allá [...] iba a la fiesta, al pelazón. Es bonito dicen, hay lindas mujeres [...] aquí vivió el abuelo de mi comadre Inés, que le llamaban Meru [...] aquí vivía, antiguamente esto era unos caserío [...] acá hacían pelazón [...] el viejo don Vicente se fue a pasear a la gente que está debajo de este loma, de ahí no regreso más [...] el quedo como jefe de gente de acá $[\ldots]$ y ahí está ahorita, él estará ahorita, nos estará escuchando[...]»7.

El relato anterior establece cómo los indígenas tienen acceso a otros mundos, y al acceder a ellos deciden no volver, es de resaltar que la entrada a este mundo se especifica en el relato como la puerta a una iglesia, lo que evidencia el efecto que la religión ha tenido en esta comunidad, como la puerta de acceso hacia un mejor mundo;

\footnotetext{
6 Relato de Ricaurte Careca 2013.

7 Relato de Argelino Victorino 2013.
} 
por otro lado se resalta la danza tradicional de la pelazón, estableciendo una convivencia entre las creencias tradicionales y occidentales, en un proceso de aculturización, deculturización e integración cultural.

Asimismo se identificaron ceibas en diferentes lugares de la comunidad, al que míticamente se le atribuye como dueńo un ser llamado la Kurupira (Figuras 9 y 10), al respecto según un abuelo de la comunidad se tiene

«Don Eliazar estaba trabajando cuando la chagra era nuevo, estaba cultivando [...] escucho un ruido que decía grrrrrrrrr [...] el miro pero no había nada, cuando el escucho parecía que se tranco dice una puerta allá atrás [...] tenía dueño pues [...] él se asustó con eso y no dijo nada $[\ldots])^{8}$.

«[...] los ancestros cuentan que la ceiba macho tiene cuento, dice que Ceiba macho esta barrigón porque antiguamente cuando Ipi y Yoi vivían juntos, Ipi tenía una cuñada, entonces Ipi se abusó de su cuñada [...] por abuzar a su cuñada le embarazo enseguida [...] cuando Ipi vivió con la cuñada se hizo más barrigona, entonces cuando llego su cuñado él le mato a la mujer, le mato y le partió, partió su barriga y le saco todo su semen del Ipi y le voto dicen encima de Ceiba macho [...] por eso quedo así barrigón [...]»?

Los relatos anteriores establecen la importancia cultural percibida en la comunidad acerca de del árbol insignia del trapecio amazónico (Ceiba Pentandra). Asimismo se funda la presencia de seres míticos que viven en este árbol (Kurupira). Es de resaltar que la ceiba macho tiene un origen mítico que se relaciona con un comportamiento moralmente no aceptado como es la traición de un hermano (Ipi) hacia la confianza que le dio su hermano.

\section{Ceibas cercanas a la comunidad}

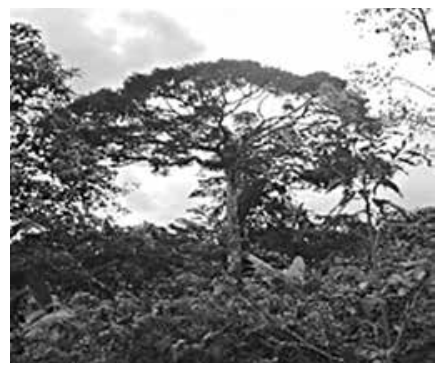

Figura 9. Ceiba Eliazar.

Foto: Ronald Quintana, 2013.

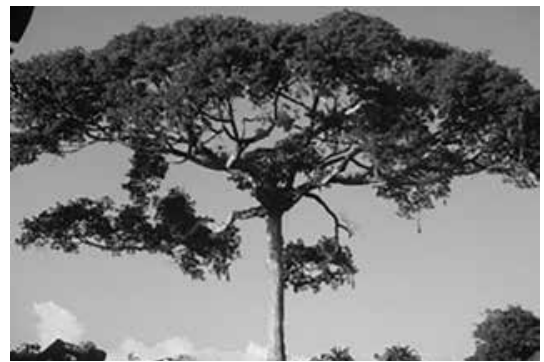

Figura 10. Ceiba de Lorenzo.

Foto: Ronald Quintana, 2013.

Por otro lado se identifica la zona del tigre del agua, un animal mítico reportado por varias etnias entre las comunidades del trapecio amazónico, cuya creencia es aceptada

8 Relato de Argelino Victorino 2013.

9 Relato de Argelino Victorino 2013. 
por el evangelio en Macedonia, lo que se evidencia en el hecho que los pastores indígenas tanto de la iglesia panamericana como de la indígena reporten historias relacionadas con la existencia de este animal.

La figura 14 (mapa cultural, dispersión humana) realiza una identificación de los lugares de importancia cultural que se encuentran cerca de la zona urbana del resguardo. En este se puede apreciar la zona del Buri Buri, espíritus antiguos que viven en las lomas altas de los barrios Monserrate e internacional, los cuales se caracterizan por llevarse la gente. $\mathrm{Al}$ respecto un abuelo de la comunidad dice

«[...] en la Loma Monserrate tenemos [...] un punto muy importante [...] se dice que de pronto hay algunos animales encantados o animales que están adentro de la loma, sobrevivientes [...] Loma internacional tenemos los mismo [...] animales que antiguamente nuestros antepasados ha cerrado adentro [...] los animales buri buri, son unos micos que son carnívoros $[\ldots] \aleph^{10}$.

Asimismo sobresale que el cementerio sea considerado un lugar sagrado, si bien es cierto las nuevas creencias de la comunidad no permiten un diálogo abierto con los espíritus de los muertos, sí se permite el diálogo con un espíritu antiguo protector con forma de boa llamado Pedrito quien se dice que habita en límite de la comunidad con el río Amazonas. Lo anterior contrasta con el poder de las iglesias cristianas de la comunidad (panamericana y la indígena) las cuales dictaminan el tipo de vida y creencias que se deben llevar en la comunidad para tener buena salud y bienestar y el poder que la comunidad aun le da al mundo de las aguas (Figura 11).
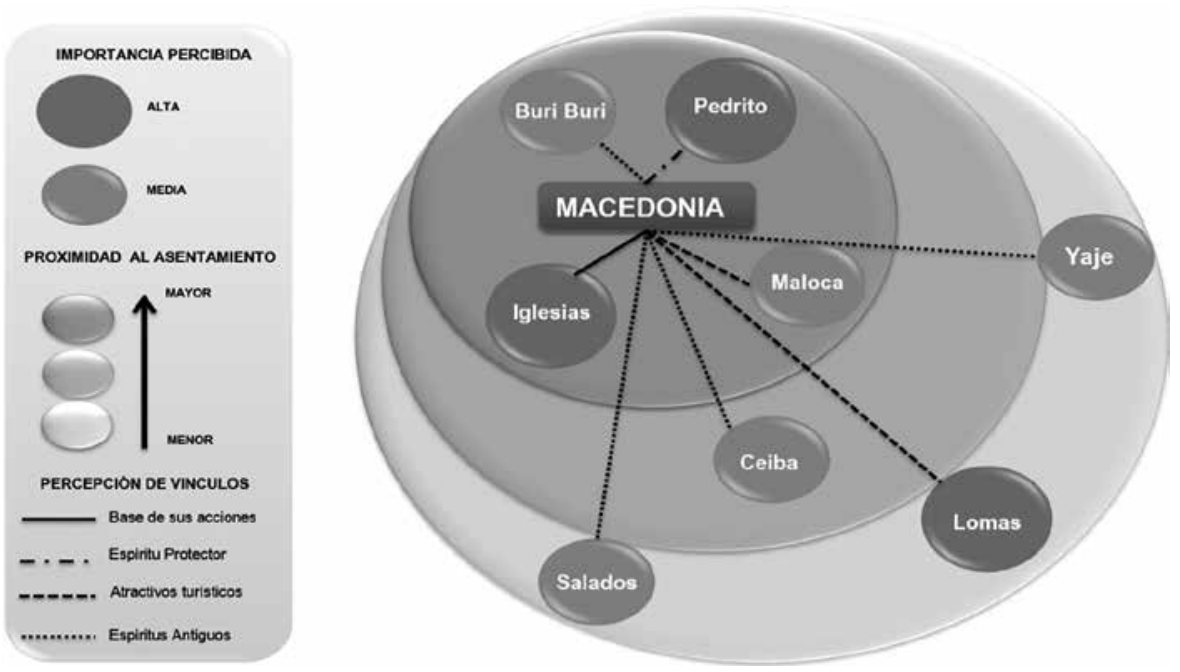

Figura 11. Sociograma cultural.

${ }^{10}$ Relato de Ricaurte Careca 2013. 
La figura 11 surge del grado de importancia que los pobladores de Macedonia le dan a sitios o espíritus que se encuentran relacionadas con la comunidad; de esta manera, la asignación de la significancia se relaciona con las menciones dadas por los pobladores y el nivel de importancia que ellos le dan a lo que se considera sagrado en la comunidad, en relación a las creencias espirituales, los ingresos económicos y la distancia de la comunidad.

Es de resaltar que los inicios de la cobertura a los servicios médicos para los pueblos indígenas se da a través de la resolución 5078 de $1992^{11}$ y que una de las justificaciones para las formaciones de las asociaciones de cabildos indígenas como Acitam, fue el fomento de proyectos de salud (decreto 1088, 1993); ya que para esa época se genera la inclusión del indígena en el seguro social (artículos 156, 157, 181 y 200 de la ley 100 de 1993).

Lo anterior llevó a la posibilidad que las entidades territoriales indígenas (ETIS) pudieran establecer convenios con entidades promotoras de salud (decreto 723 de 1997). Pero fue a partir del decreto 330 de 2001 que se le delegó al cabildo la responsabilidad de organizar y garantizar la prestación de los servicios de entidades promotoras de salud indígenas, en las que sobresale la entidad Mallamas en el Amazonas como una EPS indígena.

Macedonia reconoce cinco figuras médicas: promotor de salud, chamán, sobandero, partera y naturista (Figura 11). Pese a esto el puesto de salud departamental y la escuela de la comunidad aún no reconocen a los médicos tradicionales (chamanes, naturistas, sobanderos), tal como lo tipifica las resoluciones de la OIT y de la ONU: WHA30.49 de 1977, 5078 de 1992; WHA51.24 y la declaración de Chiang Mai en 1998.

En este orden de ideas en el "chamanismo» no se ve con buenos ojos dentro de la comunidad dado que la religión evangélica no permite el contacto espiritual tradicional con los espíritus de las plantas, los animales sagrados y Yoi e Ipi. Esto ha ocasionado que dentro de la comunidad se hable de «naturistas», término que se define como aquel hombre o mujer que tiene un amplio conocimiento sobre plantas y animales, y que puede ser usado para la curación de enfermedades pero sin ser asistido por ningún Dios diferente al evangélico.

A diferencia de los naturistas, la partera es una figura médica reconocida por la Secretaría de Salud Departamental, se caracteriza por ser una labor propia del género femenino y que se ocupa del cuidado pre- y posnatal, tanto de la madre como del nińo. La tarea de las parteras empieza desde la gestación hasta los primeros meses del bebe. A su vez, son ellas junto con las madres las que asesoran e instruyen a las jóvenes en todo lo relacionado con el ciclo menstrual y enfermedades venéreas. Cabe resaltar que

\footnotetext{
${ }^{11}$ Se adoptan normas para incentivar la investigación, recuperación, respeto y revalorización de las figuras médicas tradicionales buscando mecanismos de complementariedad.
} 
el aborto tradicionalmente era bien visto dentro de la comunidad, ya que para los tikuna el ser humano tiene dos etapas de desarrollo, una vegetal que es durante el tiempo de embarazo de la madre, y otra animal que es desde que nacen hasta que mueren.

Con relación a la figura 12 se relacionan los poderes de los espíritus tradicionales tikuna con el mundo de las aguas (parte inferior) estableciéndose así como una etnia de río, mientras que los occidentales se relacionan con el mundo del hombre occidental (parte de arriba). De esta manera, la relaciones entre la partera, el sobandero, el naturista y el chamán, se explican a continuación.

El sobandero es una figura médica reconocida por el puesto de salud, conoce de plantas y se especializa en problemas musculares, tratamientos de heridas, golpes, contusiones, huesos dislocados y rotos. Realiza sus consultas en cualquier lugar y a diferencia de la consulta médica moderna, el grado de comunicación con el paciente es mucho mayor.

El promotor de salud es el encargado de administrar el puesto de salud, se caracteriza porque es elegido por voto popular y debe pertenecer a la comunidad. Es de resaltar que desde que el autor empezó a trabajar en la comunidad en 2008, el promotor de salud ha sido el mismo y que este es el único miembro de la comunidad que tiene casa con piso de cerámica. Asimismo el promotor recibe cursos de capacitación para el tratamiento de diarrea y paludismo por parte de la Secretaría de Salud Departamental, y su desempeño es evaluado anualmente por esta misma junto con la comunidad.

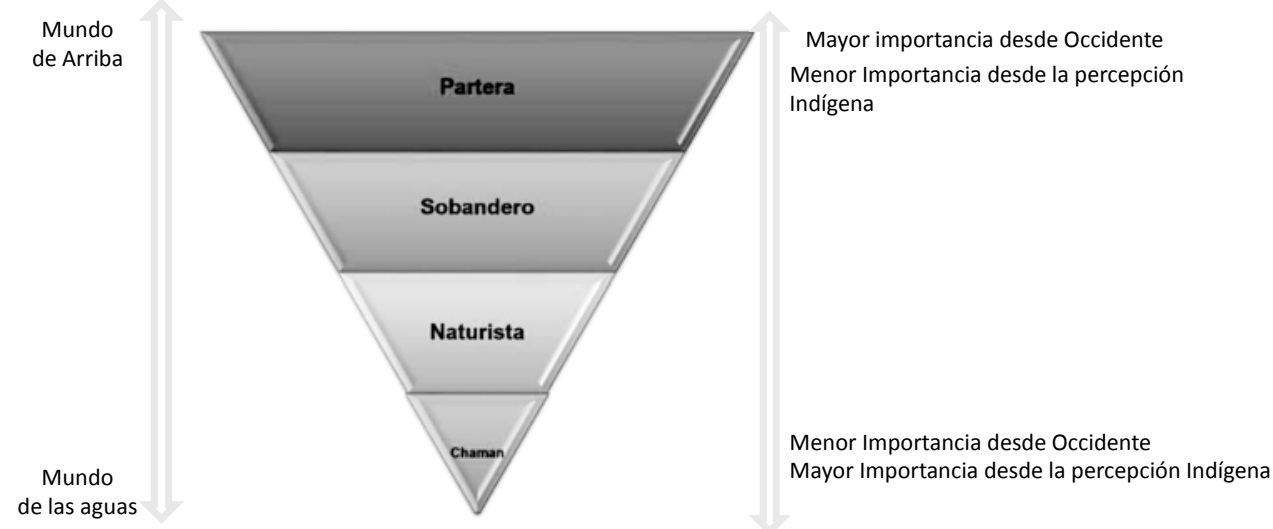

Figura 12. Figuras médicas de Macedonia en orden de importancia con la relación a los mundos de poder. Retomado de Quintana (2009).

El hecho que plantas sagradas como la coca no sean mencionadas bajo un nivel cultural, puede deberse a un rezago cultural, mediado por la implicaciones que esta planta trajo a la Amazonía y la comunidad, la cual fue bombardeada en la época en la que fue declarada zona roja por la presencia de las FARC en la comunidad. 


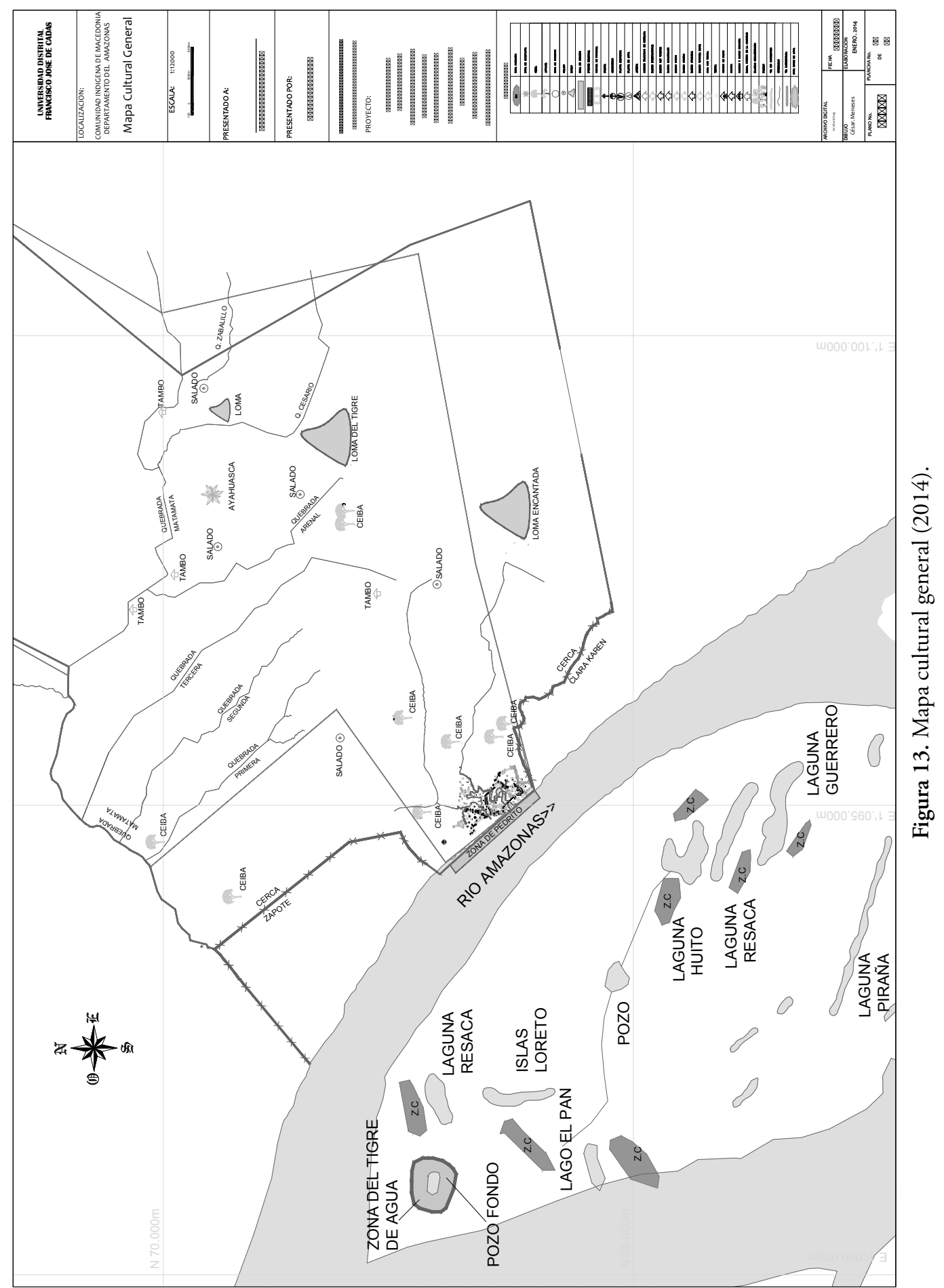




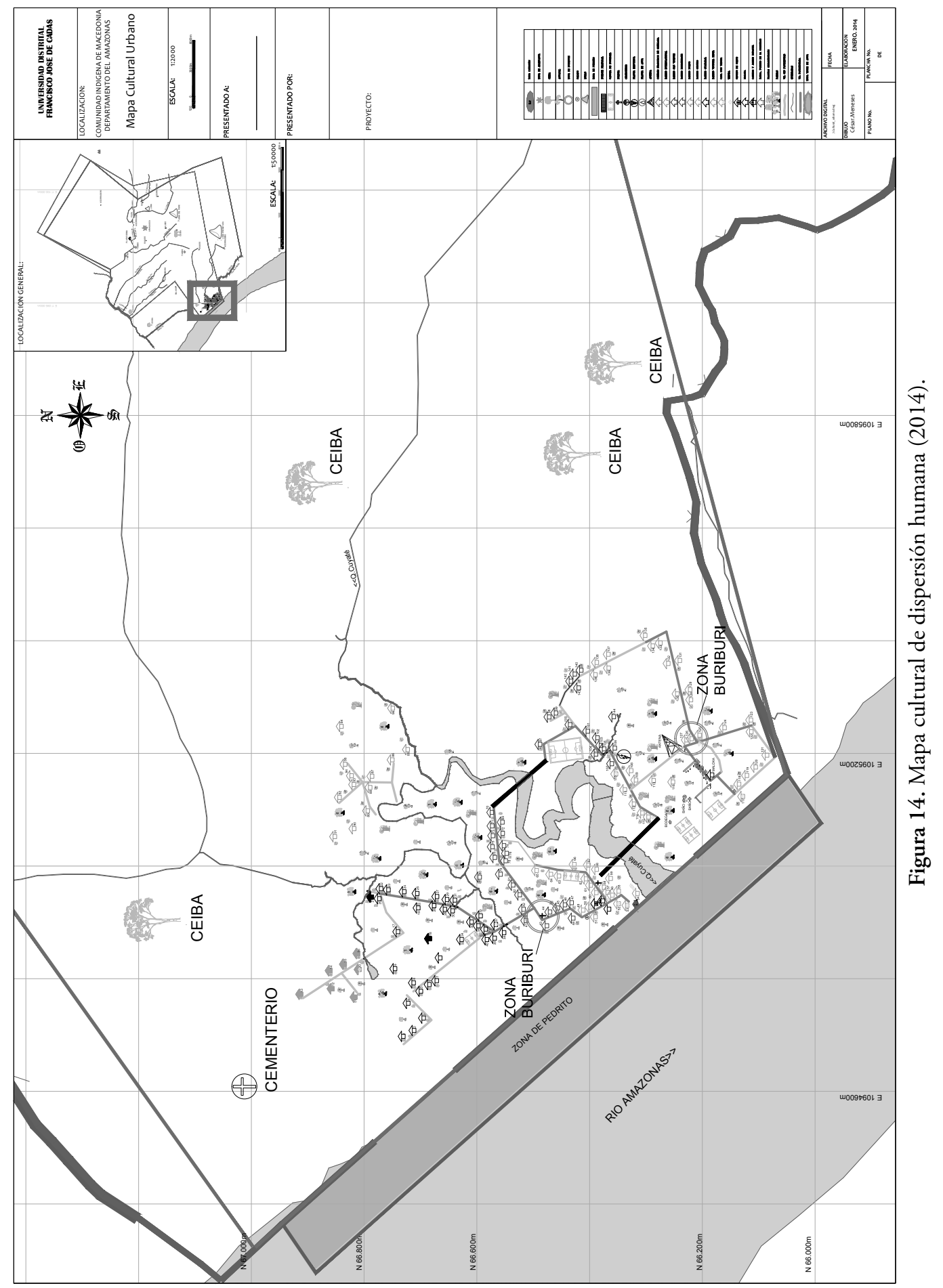


De esta manera, se da por sentado que a pesar de que la comunidad se encuentra en lo que muchos pueden denominar una lógica indígena contrapuesta a una lógica occidental absorbente, el mundo de las aguas sigue estableciendo las relaciones entre salud-naturaleza-cultura. Esencialmente este mundo sigue alimentando los discursos de la iglesia y las historias que se mantienen por interés cultural y económico. Lo anterior ha generado una consciencia indígena tanto de su riqueza cultural como del potencial económico que se posiciona en el turismo comunitario; lo que incentiva la protección de «no lugares» y la reproducción de saberes ancestrales desde la dinámicas socioculturales.

\section{Conclusiones}

Es necesario reconocer la historia de origen de las culturas en las que se trabaja para interpretar las lógicas territoriales en las que se sumerge la población a abordar; si bien es cierto que el dinamismo cultural establece que la culturas alimentan y se retroalimentan, estos mecanismos de conocimiento permiten generar procesos para que se desmitifiquen ideales del blanqueamiento y la modernidad.

La cartografía social como metodología permite expresar un sentir al realizar una aproximación a las realidades indígenas, cuyas relaciones con el territorio mantienen un misticismo ancestral a pesar del cambio de creencias radical de la comunidad. Lo anterior se ha mantenido por las historias que legitiman el ser indígena como responsable del legado intergeneracional del planeta, lo que acentúa con las respuestas positivas e incentivos económicos que se obtienen con la llegada de turistas.

En este sentido, la selva, los lugares ancestrales sagrados y los misterios asociados a estos, son enriquecidos por las historias de los cazadores, pescadores, aventureros y/o investigadores que dan muestra de hechos inexplicables como el caminar en línea recta con varios guías y cazadores expertos hacia una dirección y llegar al mismo lugar. Lo anterior se acentúa con la presencia de zonas magnéticas que descontrolan los GPS y hacen que la aguja de las brújulas giren en todas direcciones.

Existe una problemática a realizar linderaciones en la comunidad ya que actualmente existe un conflicto territorial entre los moradores de la comunidad del Vergel y los de Macedonia quienes asumen que la loma encantada les pertenece estrictamente a una comunidad por su ubicación y la delimitación dada por el Instituto Colombiano de Desarrollo Rural (Incoder) en 1983. Debido a esto se determinó que geográficamente desde la lógica occidental, la loma encantada se encuentra en territorio de los vergelitos, pero que al ser un lugar de la etnia tikuna (mayoría de vergelinos y macedónicos), este «no lugar» es un espacio supraterritorial que les pertenece no solo a una comunidad sino a toda la etnia que ancestralmente estableció relaciones con este lugar. 
El manuscrito representa un gran aporte a la cartografía digital georreferenciada de los resguardos del trapecio amazónico, ya que se generan mapas que no se encontraban en el atlas de los resguardos indígenas del trapecio amazónico. De esta manera, las explicaciones asociadas a los mapas entremezclan los conceptos de territorio desde la lógica indígena y occidental, lo que ayuda a la generación de una construcción colectiva de la percepción del territorio desde la cartografía (mítica y geográfica).

\section{Agradecimientos}

Agradezco el apoyo de Andrés Quintana y Ana Luz Arias así como el de toda la comunidad de Macedonia, quienes permitieron la realización del proyecto «Etnodesarrollo y medio ambiente: el conocimiento tradicional como estrategia para fortalecer el desarrollo sustentable y la identidad cultural de la comunidad indígena tikuna de Macedonia (Amazonas)». Proyecto financiado por el CIDC de la Universidad Distrital Francisco José de Caldas y dirigido por Jair Preciado Beltrán, cuyas orientaciones conceptuales fueron vitales al momento de organizar las ideas y construir todo el documento.

\section{Bibliografía}

Acosta Saignes, M. (1961). Estudios de la etnología antigua de Venezuela. Caracas: UCV. Alvarado Quetgles, R., Barros, C., Domínguez Roca, L., Gentile, E., González, S. G., Gutiérrez, A. I., Pedone, C., Zusman, P. (1999). Geografía. La organización del espacio mundial. Serie Libros con libros. Buenos Aires: Estrada.

Amazônia tem (2014, 22 septiembre). Amazônia tem oceano subterrâneo. Recuperado el 22/09/2014 de Agencia Fapesp: http://agencia.fapesp.br/amazonia_tem_oceano_ subterraneo_/19541/

Arocha Rodríguez, J. (1991). Autocontrol valorativo vs. recetas etnográficas. Tras el Muro. Revista del Departamento de Trabajo Social. Bogotá: Universidad Nacional de Colombia.

Auge, M. (1992). "Los no lugares» espacios del anonimato. Una antropología de la sobremodernidad. Barcelona: Gedisa.

Blanco, J. (2001). Fundaciones coloniales y republicanas de Colombia, Normas trazado y ritos fundacionales. Credencial Historia, 141.

Caneto, C. (2000). Geografía de la percepción urbana. Buenos Aires: Lugar Editorial.

Devereux, G. (1975). Etnopsicoanálisis complementarista. Buenos Aires: Amorrortu.

De Miguel, M. (1993). La IAP un paradigma para el cambio social. Documentación Social no 92.

Declaración de Chiang Mai (1998). Salve vidas salvando plantas. Tailandia. 
Decreto 1088 (1993). Por el cual se regula la creación de las asociaciones de Cabildos y/o Autoridades Tradicionales Indígenas. República de Colombia.

Decreto 330 (2001). Por el cual se expiden normas para la constitución y funcionamiento de Entidades Promotoras de Salud, conformadas por cabildos y/o autoridades tradicionales indígenas. República de Colombia.

Decreto 723 (1997). Por el cual se dictan disposiciones que regulan algunos aspectos de las relaciones entre las entidades territoriales, las entidades promotoras de salud y los prestadores de servicios de salud. República de Colombia.

Echeverri, J. \& Pérez Niño, C. Amazonia colombiana. Imaginarios y realidades. Bogotá Universidad Nacional de Colombia.

Fals Borda, O. (1992). La ciencia y el pueblo: nuevas reflexiones. En M.C. Salazar (Ed.), La investigación acción participativa. Inicios y desarrollo. Bogotá: Editorial Popular.

Fals Borda, O. (2000). El territorio como construcción social. Revista Foro, 38, 45-51.

Forman, R. (1995). Land Mosaics: The ecology of landscapes and regions. Cambridge, G.B: Cambridge University Press.

Galán-Zapata, A. (1963). Mito y superstición de la conquista americana. Buenos Aires: Eudeba.

Gandia, E. (1929). Historia crítica de los mitos de la conquista americana. Buenos Aires, Argentina: Juan Roldán y Cía.

Gasché, J. \& Echeverri, J. (2003). Sociodiversidad bosquesina: Un acercamiento desde el enfoque de una sociología comparativa. Proyecto IIAP-IMANI.

Gavilán-Pinto, V. (2012). El pensamiento en espiral: El paradigma de los pueblos indígenas. Santiago de Chile: Ebook producción.

Hemming, J. (1984). En busca de El Dorado. Barcelona: Serbal.

Hooghiemstra, H. \& Van der Hammen, T. (1998). Neogene and Quaternary development of the neotropical rain forest: The forest refugia hypothesis, and a literature overview. Earth-Science Reviews, 44, 147-183. http://dx.doi.org/10.1016/S00128252(98)00027-0

Jung, C. (1936 [1921]). Tipologias psicológicas. Buenos Aires: Sur.

Lévi-Strauss, C. (1971). La miel y las cenizas. En C. Lévi-Strauss, Mythological. Tomo II. México: Fondo de Cultura Económica.

Ley 100 (1993). Por la cual se crea el sistema de seguridad social integral y se dictan otras disposiciones. Congreso Nacional de la República Colombiana.

Ley 388 (1997). Por la cual se modifica la Ley 9a de 1989, y la Ley $3^{a}$ de 1991 y se dictan otras disposiciones. Congreso Nacional de la República Colombiana. Artículos 156, 157,181 y 200.

Ley 1454 (2011). Por la cual se dictan normas orgánicas sobre: ordenamiento territorial y se modifican otras disposiciones. Artículos: 3, 29, 37 y 329. Congreso Nacional de la República Colombiana. 
Magasich, J. \& De Beer, J. (2001). América mágica: mitos y creencias en tiempo del descubrimiento del nuevo mundo. París: Lom Ediciones.

Merino, L. \& Raya, E. (1993). El método de la investigación-acción participativa como mediación entre la teoría y la práctica de la formación del/a trabajador/a social y en el desarrollo profesional (copigrafiado). Seminario de integración teoría-práctica en la formación de los trabajadores sociales (EUTS de Alicante-C.E.B.S.), 2/3-XII-1993

Metraux, A. (1973). Religión y magias de América del Sur. Madrid: Aguilar.

Mosonyi, E. (1982). Identidad nacional y culturas populares. Caracas: Enseñanza Viva.

Mosonyi, E. (2006). Aspectos de la génesis de la educación intercultural Bilingüe para los pueblos indígenas de Venezuela. Caracas: República Bolivariana de Venezuela. Ministerio de Educación y de Deportes. Viceministerio de Asuntos Educativos. Dirección General de Niveles y Modalidades. Dirección de Educación Indígena.

Nielsen, J. \& Jorgensen, H. (1996). Kinetic model for the penicillin biosynthetic pathway in Penicillium chrysogenum. Control Engineering Practice, 4(6), 765-771. http:// dx.doi.org/10.1016/0967-0661(96)00067-6

Ocampo, J. (1988). Mitos colombianos. Bogotá: Editorial Ancora.

Olivella, M. (2008). $2^{a}$ Jornada Regional de Desarrollo Sostenible y Agenda 21 Local. Murcia: CEMACAM de Torregil.

OMS (Organización Mundial de la Salud) (1977). Resolución WHA30.49 de la 30 Asamblea General Washington D.C.

OMS (Organización Mundial de la Salud) (1998). Resolución WHA51.24 de la 51 Asamblea General Decenio Internacional de las Poblaciones Indígenas del Mundo. Ginebra.

Quintana, R. (2009). El «verdadero" guardián del oro verde, estudio etnobotánico en la Comunidad indígena de Macedonia. Tesis de grado para optar por el título de Licenciado en Biología. Universidad Distrital Francisco José de Caldas, Bogotá.

Quintana, R. (2011). Sombras invisibles: Las representaciones de niños y niñas miraña en una comunidad tikuna. Revista Chilena de Antropología Visual, 17, 92-111.

Quintana, R. (2013). Reconfiguración simbólica del territorio en una comunidad indígena amazónica. Revista Chilena de Antropología Visual, 22, 92-114.

Quintana, R. (2014). Etnodesarrollo y medio ambiente: El conocimiento tradicional como estrategia para fortalecer el desarrollo sustentable y la identidad cultural de la comunidad indigena tikuna de Macedonia (Amazonas). Tesis de grado para optar por el título de Magíster en Desarrollo Sustentable y Gestión Ambiental. Universidad Distrital Francisco José de Caldas, Bogotá.

Rae, J. (1999). Las respuestas y las preguntas de la ciencia. Museo de la Ciencia para Boston. Barcelona: Editorial Crítica.

Rahman, A. Md. \& Fals, O. (1991). El punto de vista teórico de la IAP. En O. Fals Borda y M. Rahman (Eds.), Acción y conocimiento: cómo romper el monopolio con la investigación-acción participativa (pp. 37-47). Bogotá: Cinep. 
Reichel, E. (1987). Astronomía yukuna-matapi. En J. Arias de Greiff y E. Reichel (Comps.), Etnoastronomias americanas (pp. 193-232). Bogotá: Universidad Nacional de Colombia.

Resolución 5078 (1992). Por la cual se adoptan normas técnico-administrativas en materia de Medicinas Tradicionales y Terapéuticas Alternativas y se crea el Consejo Asesor para la conservación y el desarrollo de las mismas. Artículos: 1, 2, 3, 4, 5, 6, 7, 8, 9, y 10. Bogotá.

Riechmann, J. (2009). La habitación de Pascal. Ensayos para fundamentar éticas de suficiencia y políticas de autocontención. Madrid: Los libros de la catarata.

Tuan, F. Y. (2007). Topofilia. Un estudio sobre las percepciones, actitudes y valores sobre el entorno. F. Durán de Zapata (Trad.). Madrid: Melusina.

Urbina, F. (2010). Las palabras del origen, breve compendio de la mitología de los huitoto. Biblioteca Básica de los Pueblos Indígenas de Colombia. Bogotá: Ministerio de la Cultura.

Van der Hammen, M. (1992). El manejo del mundo, naturaleza y sociedad entre los yukuna de la Amazonía colombiana. Segunda edición. Bogotá: Tropembos.

Vigneras, L. (1976). La búsqueda del Paraíso y las legendarias Islas Valladolid. Valladolid: Universidad de Valladolid.

Fecha de envío: 12 septiembre, 2015

Fecha de aceptación: 18 diciembre, 2015 